\title{
Assessment Of Us Electronic Medical Records To Guide Feasibility And Design Of The Novelty Study
}

\author{
H. K. Reddel ${ }^{1}$ M. Gerhardsson De Verdier ${ }^{2}$, A. Agusti ${ }^{3}$, R. Beasley ${ }^{4}$, E. H. Bel ${ }^{5}$, J. Hiller ${ }^{6}$, C. Janson ${ }^{7}$, A. W. Kamauu ${ }^{8}$, B. J. Make ${ }^{9}$, R. \\ J. Martin ${ }^{9}$, I. Pavord ${ }^{10}$, D. S. Postma ${ }^{11}$, D. Price ${ }^{12}$, D. Wong ${ }^{6}$, C. Keen ${ }^{2}$, A. Gardev ${ }^{13}$, S. I. Rennard ${ }^{13}$, A. Svereus ${ }^{2}$, A. Bansal ${ }^{14}$, L. \\ Brannman ${ }^{15}$, N. Karlsson ${ }^{2}$, J. Nuevo ${ }^{16}$, F. Nyberg ${ }^{2}$, X. Wang ${ }^{15}$, S. Young ${ }^{13}$, J. Vestbo ${ }^{17}$ \\ ${ }^{1}$ Woolcock Institute of Medical Research, Glebe, NSW, Australia, ${ }^{2}$ AstraZeneca, Gothenburg, Sweden, ${ }^{3}$ Hospital Clínic University of \\ Barcelona, Barcelona, Spain, ${ }^{4}$ Medical Research Institute of New Zealand, Wellington, New Zealand, ${ }^{5}$ Academic Medical Center, University \\ of Amsterdam, Amsterdam, Netherlands, ${ }^{6}$ QuintilesIMS, London, United Kingdom, ${ }^{7}$ Uppsala University, Uppsala, Sweden, ${ }^{8}$ Anolinx, Salt \\ Lake City, UT, ${ }^{9}$ National Jewish Health and University of Colorado Denver, Denver, CO, ${ }^{10}$ University of Oxford, Oxford, United Kingdom, ${ }^{11}$ \\ University of Groningen, University Medical Center Groningen, Groningen, Netherlands, ${ }^{12}$ Observational and Pragmatic Research \\ Institute, Singapore, Singapore, ${ }^{13}$ AstraZeneca, Cambridge, MD, United Kingdom, ${ }^{14}$ Acclarogen, Cambridge, United Kingdom, 15 \\ AstraZeneca, Gaithersburg, MD, ${ }^{16}$ AstraZeneca, Madrid, Spain, ${ }^{17}$ The University of Manchester, Manchester, United Kingdom
}

\section{Rationale}

Since asthma and chronic obstructive pulmonary disease (COPD) have often been viewed as distinct diseases, past biomarker and pharmacotherapy studies have frequently focused on each disease separately, thereby limiting the possibility of identifying the overlapping biological mechanisms between them. NOVELTY (a NOVEL observational longiTudinal studY on patients with asthma and/or COPD) is a prospective, global, cohort study enrolling $\sim 15,000$ patients aged $\geq 12$ years with a diagnosis or suspected diagnosis of asthma and/or COPD. NOVELTY aims to describe patient characteristics, treatment patterns, and illness burden over time in clinical practice, and to use biomarkers and clinical parameters to identify phenotypes and endotypes associated with differential outcomes. Electronic medical records (EMRs) were analyzed to understand the potential US patient population for NOVELTY, and assess EMRs as a data source for such research.

\section{Methods}

EMR data were collected from four healthcare systems in the Anolinx eResearch Network (A-EMR 1-4; Table), and from the QuintilesIMS US EMR database (IMS EMR). Patients with asthma, COPD or both diagnoses were identified using the International Classification of Diseases-9. Disease severity was classified using treatment- and/or lung function-based algorithms. EMR variable coverage was evaluated over a 12-month period.

\section{Results}

EMRs from 654,122 patients with asthma, 735,453 with COPD, and 83,857 with both diagnoses were identified. Asthma severity was classified in A-EMR 1, A-EMR 4, and IMS EMR databases: $23.5 \%, 1.5 \%, 0.7 \%$, and $0.1 \%$ of patients had mild, moderate, severe and very severe asthma, respectively (unclassifiable in $73.8 \%$ across the databases). COPD severity was classified in all databases: $26.7 \%, 12.0 \%$, and $21.9 \%$ had mild, moderate and severe/very severe COPD, respectively (unclassifiable in 39.3\% across the databases). In the selected EMRs, many respiratory-relevant variables were infrequently recorded, or were not in searchable formats (Table). Some variables (e.g. exacerbations) may have had low percentages due to low incidence. Patient-reported outcomes (PROs) and symptom data were not documented. 


\begin{tabular}{|c|c|c|c|c|c|c|c|c|c|c|}
\hline & \multicolumn{2}{|c|}{ AEMR 1} & \multicolumn{2}{|c|}{ AEMR 2} & \multicolumn{2}{|c|}{ AEMR 3} & \multicolumn{2}{|c|}{ AEMR 4} & \multicolumn{2}{|c|}{ IMS EMR } \\
\hline $\begin{array}{l}\text { scope of } \\
\text { databane }\end{array}$ & $5750 \mathrm{pm}$ & ysiouns & $\begin{array}{l}>1,7 \\
\text { hosph } \\
\text { dinics } \\
\text { other to }\end{array}$ & $\begin{array}{l}\text { con } \\
\text { cals. } \\
\text { and } \\
\text { oclites }\end{array}$ & $\begin{array}{l}32.5 \\
\text { physix }\end{array}$ & & $\begin{array}{l}\text { Sop } \\
\text { pract } \\
\text { oupat } \\
\text { ambulate } \\
\text { or }\end{array}$ & $\begin{array}{l}\text { canos } \\
\text { cess } \\
y \text { cinios }\end{array}$ & $\begin{array}{l}2 \$ 5,0 \\
\text { physic }\end{array}$ & $\begin{array}{l}000 \\
\text { cianss }\end{array}$ \\
\hline Variable & Asthma & COPD & Adthma & cono & Asthera & COPD & Asthma & COPD & Asthma & COpD \\
\hline Agelsex & 900 & 100 & 100 & 100 & 100 & 700 & 100 & 100 & 100 & 100 \\
\hline$B M$ & 97 & 97 & $\infty$ & $\infty 0$ & 94 & 16 & 100 & 100 & 77 & 80 \\
\hline Smoking status & 98 & 97 & 88 & 88 & $\infty$ & $\mathscr{Q}$ & 100 & 100 & $0^{\circ}$ & $\sigma^{\circ}$ \\
\hline Exacertabons & 38 & NR & 23 & NR & 36 & NA & 32 & NR & 10 & 11 \\
\hline Prescriptons & 73 & 66 & $>75$ & $>75$ & 27 & $\theta$ & 100 & 100 & 44 & 45 \\
\hline Alengy hisacy & 100 & 100 & -90 & -90 & 97 & 98 & $>60$ & $\times \$ 0$ & NR & NR \\
\hline Bicosd eosimophis & 50 & $\pi 0$ & $>70$ & $>70$ & 41 & 5s & $>60$ & $=0$ & 11 & 11 \\
\hline FEV & * & 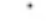 & * & 17 & " & • & * & - & NRR & NR \\
\hline rve & - & * & $\cdot$ & 11 & - & - & ' & - & NR & NR \\
\hline per & NR & NR & NR & NR & NR & NR & NR & Na & NR & NRR \\
\hline Chest $x$-ray & 36 & 54 & $>35$ & sas & 27 & 45 & -10 & -10 & NR & NR \\
\hline Monptalcaton & 22 & 34 & 21 & 21 & 20 & $x$ & -10 & -10 & NR & NR \\
\hline
\end{tabular}

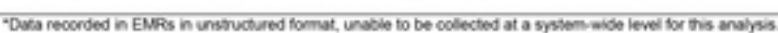

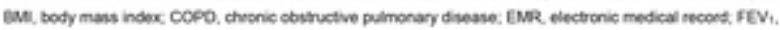

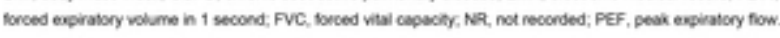

\section{Conclusions}

EMR analysis allowed assessment of US patient numbers potentially eligible for NOVELTY. In the selected EMRs, disease severity was unclassifiable for many patients, suggesting that treatment or lung function data were not collected, or not readily retrievable from EMRs. Several key variables for airways disease (e.g. lung function and $\mathrm{PRO} /$ symptoms) were not readily available with sufficient completeness and frequency over time. Primary data collection for NOVELTY will therefore use electronic case report forms, with the aim to have EMRs provide supplementary data.

This abstract is funded by: This study was funded by AstraZeneca.

Am J Respir Crit Care Med 2017;195:A2032

Internet address: www.atsjournals.org 